\title{
Lessons Learned from a Structured Undergraduate Mentorship Program in Computational Mathematics at George Mason University
}

\author{
John Wallin ${ }^{1}$ and Tim Sauer ${ }^{2}$ \\ 1 Department of Computational and Data Sciences, College of Science, \\ George Mason University, Fairfax, VA 22030, USA \\ 2 Department of Mathematical Sciences, College of Science, George Mason \\ University, Fairfax, VA 22030, USA
}

\begin{abstract}
We present the results from the first two years of the Undergraduate Research for Computational Mathematics (URCM) program at George Mason University (Mason). In this program, students work on a year-long research project in Computational Science while being supervised by a mentor. We describe the structure and goals of this program along with some observations about the elements that we have found that have been challenging in its implementation. Finally, we will provide a summary of the outcomes of the first two years of this project 1
\end{abstract}

\section{Introduction}

In the Spring of 2007, the Department of Mathematical Sciences and the Department of Computational and Data Sciences (CDS) at George Mason University received funding from the National Science Foundation to create an undergraduate mentorship program in computational mathematics. This project was funded through the Computational Science for Undergraduates in the Mathematical Sciences (CSUMS) program for a five one-year cohorts. In the spring of 2007, the project selected the first ten students in this year-long program. A second cohort was selected in the spring of 2008 .

NSF originated the CSUMS program for students in the mathematical sciences "to better prepare these students to pursue careers and graduate study in fields that require integrated strengths in computation and the mathematical sciences." [1] Unlike the NSF funded Research Experiences for Undergraduates (REU) program where students work on a project over the summer, the CSUMS program is allows students to work on their own independent research projects over a full year under the direction of a faculty mentor. For the students in our

${ }^{1}$ The development of the GMU Computational and Data Sciences undergraduate program is sponsored by the NSF CSUMS (Computational Science Training for Undergraduates in the Mathematical Sciences) program, through award \# DMS0639300 .

G. Allen et al. (Eds.): ICCS 2009, Part II, LNCS 5545, pp. 103-110, 2009.

(C) Springer-Verlag Berlin Heidelberg 2009 
program, this was their first exposure to working on a long term research project. As summarized by the National Academy of Sciences, ". . . the one-on-one mentoring that takes place in supervised undergraduate research is one of the best predictors of students' professional success." [2]

The goal of the George Mason University URCM program is to create a oneon-one mentoring program in the computational sciences for undergraduate students in the mathematical sciences. In this program, we hope to enhance the professional success of our students by placing them in supervised, independent research projects. This is being done by

- exposing undergraduate students to the applied mathematics, science, and computer science used in cutting-edge computational science projects through mentorship, classes, and seminars,

- developing the formal and informal learning environments that allow students to be successful at developing, completing, and presenting their projects,

- developing a peer learning community by encouraging structured student interaction through classes, seminars, labs, as well as formal and informal meetings in their research group,

- creating close ties between student and mentor, where the student can receive ongoing feedback on the project's progress as well as constructive feedback on personal strengths and weaknesses in becoming a professional mathematician and scientist,

- extending this program beyond the five-year period that is funded by NSF by matching undergraduate students to scientists who have existing grants both on the Mason campus and in the larger community.

The students in the program work in a year-long funded research project under the direction of a faculty mentor. Because of NSF guidelines, all the students in the program are required to be mathematics majors. In our program, these students are generally in their junior or senior year. Students apply in March, and a selection of the students for the yearly cohort is made by the beginning of April.

The students who have participated in this program have worked on a wide variety of computational science research. Although individual research projects ranged from chemical phase transitions and material structure to computational hemodynamics, they all had the common theme of numerical and mathematical modeling of physical systems. Unlike with individual student research programs, this common theme provides a unifying element of the program that is used to create support structures that benefit all the students.

Student participation in the project begins at the beginning of the first summer session in late May. During this summer semester, all the students are required to take a course in Numerical Partial Differential Equations (PDE). This class is designed to fill in the background the students need for their research projects as well as help build the peer relationships and support structure they will need as they transition to research. As a prerequisite, we ask the our student complete a one-semester course in basic numerical methods. In parallel with the numerical PDE course, the students also participate in a daily lab session where they learn how to use basic computational tools and programming languages. After the PDE 
class ends in early July, the students continue to attend the lab session twice a week and start working with their advisors on research projects. Throughout the summer, these lab sessions are kept very informal and are designed to help fill in the computational background they need for their research projects.

In both the Fall and Spring semester, students are required to attend a onecredit seminar that meets once a week. In this seminar, students are given information on careers, publications, graduate school, and also required to present frequent updates on their research. A major focus of the seminar is to let students polish their public speaking and writing skills as they prepare to go to conferences, create their posters about their work, and write papers. The seminar also provides a regular venue for students to discuss the problems they are having in their research projects.

In the URCM program at Mason, two students are paired together with one or more faculty mentors. The students work on different aspects of the same project, so they can have a peer support network outside the classroom. The students may sign up up to six credits for undergraduate directed reading and research over their research project so they may receive academic credit for their work. The students are also given a $\$ 10,000$ stipend over the year long project, and loaned a laptop computer so they have a portable platform for their computing and presentations. Travel to conferences, software costs, and publication charges are also covered in the grant.

\section{Observations}

As the Director of the mentorship program, Dr. Wallin worked with all the students in the summer laboratory and then interacted with them the weekly seminar that he directed. He also interacted with all the mentors on a weekly basis. Dr. Sauer was the PI for the grant, and also worked closely with both the fauclty and the students. In these capacities, we have compiled feedback from both the students and the mentors. Because only thirteen students have been in this program so far, the results are anecdotal. We will be using the pronoun "we" to describe these findings, since they reflect the informal consensus of the groups involved. We believe that these observations reflect some of the underlying issues that others might encounter in similar undergraduate research programs in computational science.

First, the success of students seemed to be somewhat correlated on the complexity of the software that they used in their projects. If students developed their own simple codes, it seemed they remained more engaged and motivated in the research work. This finding may be more directly related to the students being mathematics majors, not computer science or computational science majors.

Before starting work on their projects, our students had not been exposed to the challenges of working with "black box" programs. We define the term "black box" in this context to mean programs too complicated for any one person (particularly an undergraduate mathematics student) to completely understand. These types of programs are commonly used in complex calculations across the 
computational sciences to simulate diverse problems such as fluid flow or material science. Most of the students in our program were interested in approaching the higher level more theoretical questions rather than doing these production calculations, even if those calculations were tied to very engaging projects.

One issue with using "black box" in undergraduate research projects might be the learning curve associated with these complex systems. However, it seemed like most of the frustration that these students felt was the lack of connection between their classroom studies and their research work. While computational science projects tend to focus on projects of very high complexity with difficult interconnections, this paradigm does not seem to map as well to the typical background of undergraduate mathematics majors we found in our programs. In general, it seemed difficult to move our students beyond the simpler Matlab/Octave tools toward complex programs and compiled programming languages.

Second, the students in the program often did not engage fully in the research work until they were forced to present their work in our weekly seminar. At the beginning of the fall semester, about half of the students had not made significant progress on their research projects during the first year of the program. When they were required to make class presentations and given deadlines in their schedule, the students systematically started making good progress. The quality of the presentations, their understanding of the problem's context, and their research results all came into focus during the fall semester.

Some of the delay in progress might have been from not understanding the expectations being set by their advisors. We believe that part of the problem can be attributed to the difficulties in the transition between classroom learning and research, as well as to procrastination that all of us feel until a deadline is upon us. Even so, setting and enforcing milestones with definable metrics in these research projects seems to be very important in promoting student learning, particularly in the first months of a long-term project. Even though the students were working on independent projects, they needed regular direction from their mentors to continue making progress. As students became more vested in the research work, most began to develop their own project schedules and started integrating research more into their weekly schedule.

Third, we found that the peer support planned in this project was only partially successful at helping students overcome difficulties they encountered in their research. Often a student would turn to his research partner for help, but busy schedules and geographic considerations made it difficult to get and give help. Most of the students in our program and across Mason in general lived off campus. The commute times and lack of face to face contact outside the normal university hours probably worked against this collaboration. The students would often turn to their research advisor instead of their research peer for help.

In contrast, we did find that the students immediately started using text messaging, Facebook, and video conferencing through their laptops during their class to talk about homework assignments during the summer PDE class. This transition took place in days, perhaps even hours, after we gave them all laptops. When the students were working as a class on the same problems, they tended to 
function together extremely well. This collaboration did not translate as well as we hoped when they started working on independent projects. Even though two or three students were assigned to very similar projects with the same advisor, the differences between the projects and lack of common focus seemed to be a barrier for effective peer support. In the second cohort, we worked to instill the expectations that the students in peer groups should meet on a weekly basis. This seems to have created a better system of peer support during the second year of the project.

Fourth, students who signed up for academic credit for their research work were generally more productive than those who did not sign up for these research credits. Some students who tried to balance a full class load with no time explicitly budgeted for their research activities. In the most extreme case, some students tried to sign up for a full course load during summer. When they did this, their research often was viewed as secondary activity that was pushed aside when there were no nearby deadlines. When students explicitly budgeted their time through credit hours, this problem was significantly reduced.

Fifth, peer support of mentors is just as important as peer support of students. Even experienced faculty who had supervised graduate students had some trouble effectively mentoring undergraduate students. Regular, informal meetings between the mentors seemed to help them see how other students and mentors were working together. Eventually, this helped make the mentorship experience more consistent between the students.

In our first year, the faculty mentors were split in two different buildings. This inadvertently led to less frequent contact between the faculty, despite efforts to encourage communications. During the second cohort, all the faculty mentors had offices close together leading to more regular discussions about their students and the program. It seems this extra support seemed to help the students in the program become more successful in their research projects earlier in their yearlong projects.

Finally, we have found that recruiting students into this project was more difficult than expected. Even with the generous stipend, the laptop, and the experience that students would gain through the project, many students in the mathematical sciences were reticent to even apply to the program. When we asked students who were in the program why other students were not applying, we found several surprising answers. Some students in our program reported that their friends did not want to get involved in research, since they had no plans to go to graduate school. Others students reported that their friends were not interested in either doing research in or getting a job in applied mathematics and computing.

It seems that many undergraduate students in the mathematical sciences (and probably beyond) don't have a good understanding of the jobs they are likely to do after they graduate since most studies indicate that the vast majority of jobs for majors across the sciences and mathematics are IT related. [3]. 


\section{Program Outcomes}

Beyond our observations of the elements that seem to help and hinder our mentorship program, it is important to consider the tangible outcomes of this project. All but one of the thirteen students have presented both oral and poster papers for external conferences. Most of the students presented papers at both regional and national conferences, and one was given an award for his poster at the San Diego meeting of the American Mathematical Society in 2007. The confidence that the students had in creating and giving presentations along with the quality of these presentations was dramatically enhanced by the practice in the seminar class.

The skills that students exhibited with software tools also increased dramatically through the project. Most of our students had no familiarity with Unix at the start of the project, and were experts by the end of the year. The students'skills at using high level tools like Matlab/Octave also greatly increased during the program. By the end of the year, all of the students felt comfortable putting complex PDE system into Matlab or Octave. Many of these students had done very little programming at the beginning of their research project, but were very comfortable writing these types of codes by the end of their year.

The quality of the final research projects we saw in the program was very high. Most of the mentors felt that the work being done by their undergraduate students was at the level of first and second year graduate students. The students also noted this when they compared their work to other peer groups at conferences. In particular, one student reported that he felt his work was "just average" when he looked at the other posters at a conference. He didn't realize at the time that there were only two undergraduate students at this poster session of about forty graduate students.

One of the least quantifiable elements of these projects was the excitement that our students felt about being able to participate and carry out significant, independent research projects under the direction of a real scientist mentor. Having the students participate in regional and national conferences also opened up the world of mathematical and computational research to them, and let them understand the research process from conception to presentation. Overall, our students reported very positive feelings about the program, despite some of the difficulties they encountered in their projects.

Of the nine students in the first year cohort, all but one have gone on to take graduate courses after graduation. Six are pursing doctoral degrees, and two others are working masters degrees. Four of the six students pursuing the Ph.D. are studying either Computational Science or Applied Mathematics. The remaining doctoral students are working in operations research or medicine. The only student not currently enrolled in graduate studies is taking a year off before starting medical school. It is important to note that less than half of students had seriously considered graduate school before they started the project. Based on the status of the first cohort, we strongly feel that this program helped change the attitudes our students had toward research in Computational Science and Mathematics. 


\section{Summary and Conclusions}

We have found a great deal of unexpected challenges in this project, and are still learning how to improve the experience for our mentors and our students. Based on our experiences, we make the following recommendations for other similar programs:

- Pick projects that help the students apply their classroom work directly to their research projects. Having students switch too quickly into complex software systems can make it difficult for them to make this connections, and make it seem like their studies are unrelated to their research work.

- Make sure to create and enforce milestones through out the program. Although this is an independent research project, students learning how to do research need structure particularly in the first few months of the project.

- Set expectations for peer meetings and peer support during the project. Make sure the students understand that they are expected to work together, and keep the projects in peer groups similar enough so that they can benefit from each other's experience.

- Strongly encourage students sign up for directed reading and research credits when they are in a mentorship or research program. Students tend to over schedule themselves if time isn't put into their academic schedules.

- Build informal activities to provide peer support of the mentors. This type of support is very useful in normalizing expectations and keeping the mentors engaged in the student projects.

- Try to minimize geographic barriers to collaboration both between student and between mentors. Make sure regular meetings occur within and between the different groups.

Despite some of the initial problems, we are very happy with the outcomes of our students both in terms of their research work and their careers. We feel that our program contributed to their professional development, and has provided them with a strong basis for further academic work and for their future jobs.

Now that the new major and minor in the Computational and Data Science is in place at Mason, we hope to see future double majors in this program and minors from the department of Mathematics in these programs. We feel that the minor will be particularly attractive to these students since many of the requirements are already met by their participation in this program via the numerical methods and research courses they are already taking in their mentorship. With these programs in place, we feel our students will students develop the computational skills they need in their careers or for future graduate work.

Creating projects that for the students that were independent, exciting, and cutting-edge yet suited to the technical backgrounds of our undergraduates took a high level of commitment from our mentors. Despite the challenges, we have all seen a great return on the time we invested in this project as we as we watched the first cohort progress though the program, present papers, and graduate. As 
the second cohort progresses through their program, it is gratifying to see them transitioning to research faster and broadening their knowledge of how to solve cutting edge problems using computational science.

\section{References}

1. Computational Science Training for Undergraduates in the Mathematical Sciences (CSUMS), National Science Foundation Solicitation 06-559 (2008), http://www.nsf .gov/funding/pgm_summ.jsp?pims_id=13655

2. Fox, M.A., Hackerman, N. (eds.): Evaluating and Improving Undergraduate Teaching in Science, Technology, Engineering and Mathematics. The National Academy Press, Washington (2003)

3. Testimony before the House Subcommittee on Science, Bruce Mehlman, Technology, and Standards Subcommittee, June 24(2002),

gop.science.house.gov/hearings/ets $02 /$ jun $24 / \mathrm{mehlman} . \mathrm{htm}$ 